\title{
Development of Sports Medicine in India and Recent
} Advances

\author{
Arumugam Sivaraman ${ }^{1}$, Suresh Perumal ${ }^{1}$, Prakash Ayyathurai ${ }^{1}$, Thiagarajan Alwar ${ }^{1}$
}

\section{Abstract}

Sports are beneficial for us both at individual and social levels. Sports Medicine is an ancient subject. Sports medicine in India is steadily growing. Sports activities have witnessed a remarkable upswing in the recent times, and we require a huge number of sports support staff. There is an urgent need to look at capacity building of institutions in our country. Government of India has launched several measures for sports development including the Khelo India Scheme. Sports Medicine is a multidisciplinary field with a broad objective, focusing on holistic athlete care and not only injuries. Injury prevention, peak performance, high competition levels, and surge in number of sports events has resulted in the development of Sports Medicine. It uses a multi-modal approach including new strategies and technologies. Technology is helping to analyze and create new strategies for boosting performance. Genetic technology can improve performance, health, and safety. Latest advances in sensory garments, helmets, mouth guards, monitors, and wearables have made sports medicine indispensable. Recent advances like High Altitude Simulation Training, Antigravity treadmill, exoskeletons, bio-harnesses, smart fabrics, Virtual and Augmented Reality are revolutionizing sports. Centre for Sports Science at Sri Ramachandra Institute of Higher Education and Research (deemed to be university) in Chennai is a center of excellence for Asian Football Confederation and International Cricket Council in India. It serves as a hub for Sports Science Training, Education and Research in India applying the latest scientific advances in sports medicine and sports science. Sports have grown from being just a source of entertainment to a social culture and also as a gratifying career option for many. This trend is expected to evolve further with a bright scope for everyone connected with the sports ecosystem,

Keywords: Sports Medicine, sports science, injury prevention, performance enhancement, sports rehabilitation, wearables, athlete monitoring, GPS tracking system, anti-gravity treadmill, virtual reality, augmented reality, sports genetics.

\section{Introduction}

Sports are beneficial for us both at individual and social levels. It helps in holistic body and mind development at individual level while it could influence the development of a nation earning pride to the country. Major sporting nations are known do perform well on health indicators too.

India has a younger demographic profile compared to most other countries in the world. This should augur well for sports. However, this enormous human resource potential has not reflected in the medal tallies of international sports. India has won only 35 medals in the last 100 years of Olympic history. This has made the governments and policy makers sit up and focus more on scientific methods for sports development including sports medicine.

\section{History of Sports Medicine}

History of Sports Medicine

Sports Medicine is an ancient subject. History has recorded Galen appointed as the team doctor of Gladiators in the Pergamum kingdom in the 2 nd century (Fig. 1).

The world's first sports medicine set up was established at Dresden, Germany, way back in 1911. A "First Congress for the scientific investigation of sports and physical exercises" was also held in Germany the next year. The term "sports physician" was coined by Arthur Mallwitz in 1913. A sports medicine journal was started by the French Society of Sports Medicine in 1922. Further sports-related medical societies followed
${ }^{1}$ Department of Arthroscopy and Sports Medicine, Sri Ramachandra Institute of Higher Education and Research (Deemed University), Chennai, Tamil Nadu, India.

Address of Correspondence

Dr. Thiagarajan Alwar,

Department of Arthroscopy and Sports Medicine, Sri Ramachandra Institute of Higher Education and Research

(Deemed University), Porur, Chennai - 600 116, Tamil Nadu, India.

E-mail: drkatn@csstrucoach.in

Submitted Date: 7 Nov 2021, Review Date: 9 Nov 2021, Accepted Date: 12 Nov 2021 \& Published Date: 31 Dec 2021

Journal of Clinical Orthopaedics |Available on www.jcorth.com | DOI:10.13107/jcorth.2021.v06i02.447 This is an Open Access article distributed under the terms of the Creative Commons Attribution NonCommercial-Share Alike 4.0 License (http://creativecommons.org/licenses/by-nc-sa/4.0) which allows others to remix, tweak, and build upon the work non-commercially as long as appropriate credit is given and the new creation are licensed under the identical terms. 


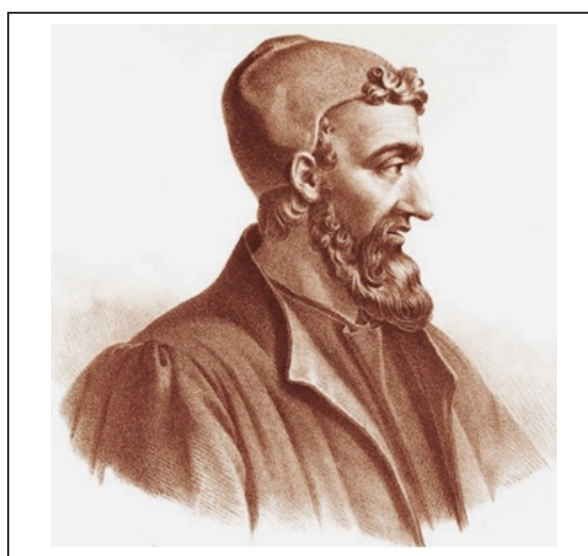

Figure 1: Galen - Father of Sports Medicine.

suit, publishing journals in 1921 in The Netherlands and in 1922, in Switzerland. An "Association International Medico Sportive" was founded by a group of physicians from 11 countries who participated in the 2nd Winter Olympic Games in St. Moritz. It became the "Fédération Internationale de Médecine Sportive (FIMS)" in 1934. The International Olympic Committee has recognized FIMS as "the designated competent international organization for biological and medical research to medicine and sport and medical care of athletes." FIMS has since been recognized by the World Health Organization and the International Council of Sports and Physical Education also.

The establishment of further sports medicine societies followed:

- Italian Sports Medicine Federation (FMSI) - 1929

- Polish Sports Physicians Association established-1937

- Finnish Society of Sports Medicine 1939.

In 1945, Charles University in Prague

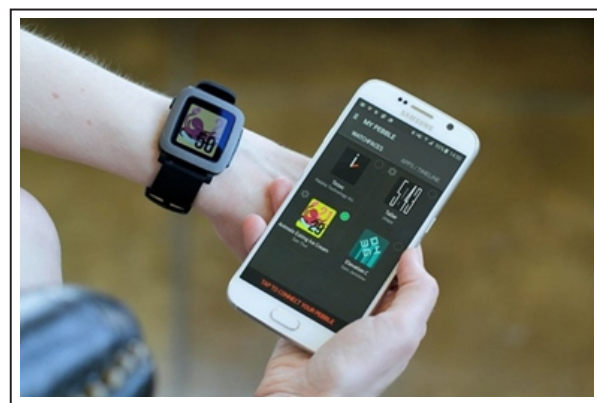

Figure 4: Pebble TimeApp.

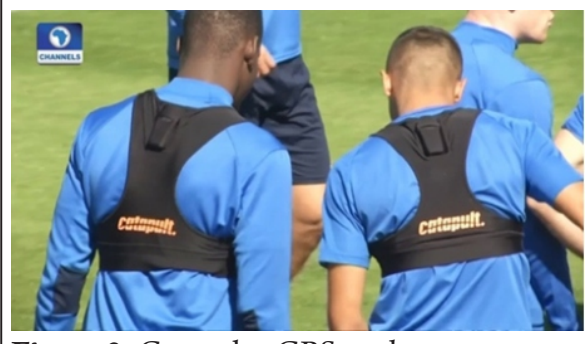

Figure 2: Catapult - GPS tracker system.

(Czech Republic) established the first institute of sports medicine in a medical faculty. In addition to the abovementioned countries, Scandinavian, Mediterranean and Balkan Countries also have longstanding traditions in sports medicine. The first School of Specialization in Sport Medicine was established in Milan, Italy, by Professor Rodolfo Margaria in 1958, after the end of 2nd World War. Today, Italy is a pioneer in sports medicine and has a good public system of pre-participation medical examinations in sports.

Today leading organizations such as the medical committees of FIFA and IOC along with other bodies such as American College of Sports Medicine and Australasian College of Sports and Exercise Physicians are largely governing the global sports medicine scenario $[1,2$, $3,4]$.

\section{Sports Medicine in India}

Sports medicine in India is steadily growing. It started developing in the 1970s with the advent of "Indian Association of Sports Medicine." Netaji Subhas National Institute of Sports, a

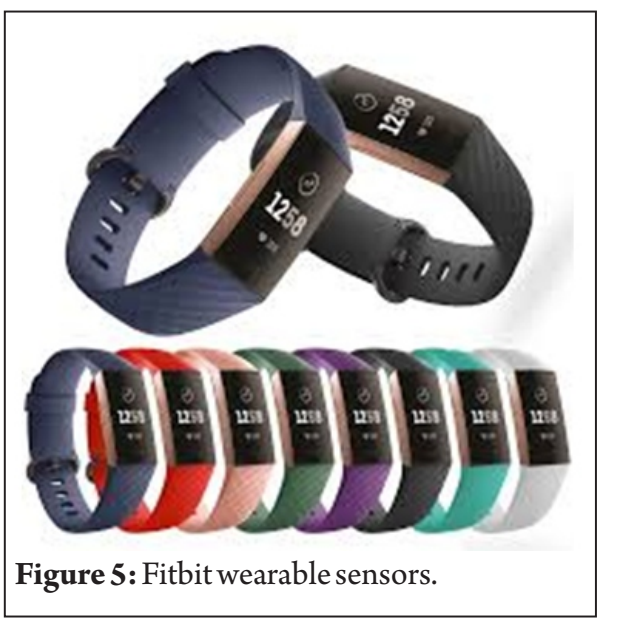

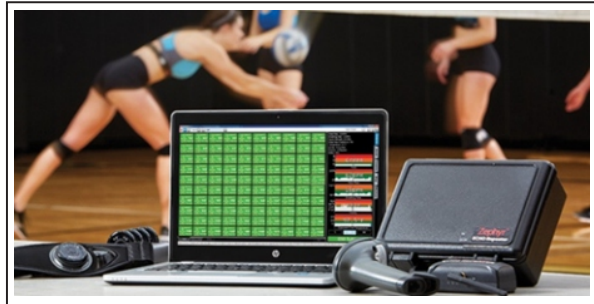

Figure 3: Zephyr Bio-harness.

dedicated educational institution for sports medicine was started in 1983 at Patiala. This institute offers diploma in sports medicine and has many top sports medicine specialists as its alumni. The postgraduate masters' degree in Sports Medicine (MD) was started first in Sri Ramachandra University, Chennai, and then by Guru Nanak Dev University, Amritsar.

Since then, many other institutions including Armed Forces Medical College in Pune, and Vardhaman Mahavir College, Safdarjung Hospital in Delhi, have started MD sports medicine courses. A National Sports University has been set up at Imphal, Manipur and new departments for sports science are being started at various Government and private institutions.

\section{Scope of Sports Medicine in India}

A Govt. sponsored study done in 2011 estimated that there will be more than a million new sports persons by 2017 in India [5]. It could have doubled by now. This finding stresses the point that India requires a staggering number of sports personnel (support staff) close to half a million. Though there are many institutions offering sports education programs, mainly in Physical Education stream, with thousands of students

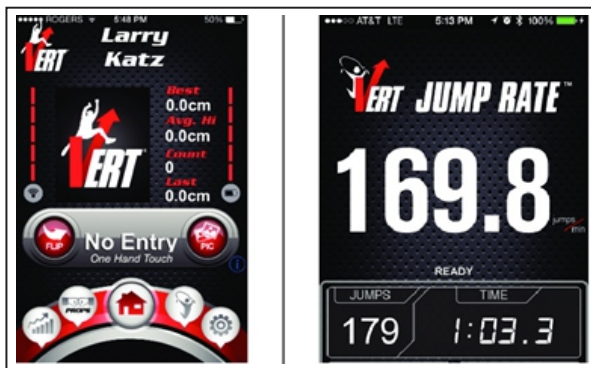

Figure 6: "Vert” Jump App.

(C) | Journal of Clinical Orthopaedics | Published by Orthopaedic Research Group | Volume 6 | Issue 2 | July-dec 2021 | Page 36 


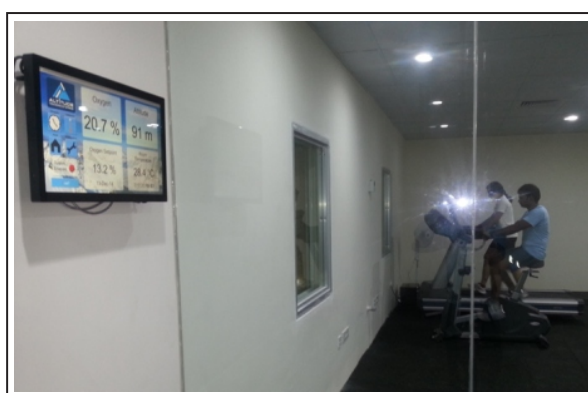

Figure 7: High altitude training chamber.

passing out every year, only around $15 \%$ continue in sports careers. This has been attributed to the lack of proper sports science training, opportunities for higher learning, global exposure and paucity of career options. (6)

The natural progression of most sports loving/performing students in Indian schools is to continue their education in streams such as "Bachelors in physical education- (B.P.Ed)," which generally enables them to become a sports or Physical Education teacher at school level. The lack of better opportunities, including the exposure at school level to branch out into support activities in the sports and physical wellness sectors exemplifies the urgent need to look at capacity building of Institutions from the very basic level and upward right from the bottom of the pyramid. There is also a pressing need to synergize the learning/academic atmosphere to fully capture the benefits of a sport capable nation. Institutional capacity building of these institutes in a structured manner can have far reaching consequences in changing the sports scenario in India.

On the brighter side, sports activities have witnessed a remarkable upswing in the recent times. Popular league events

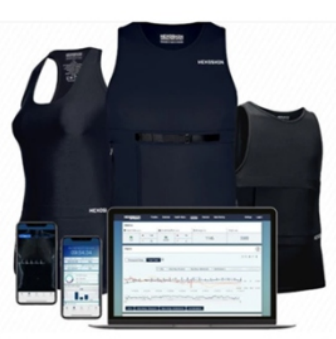

Figure 10: Hexoskin shirts.

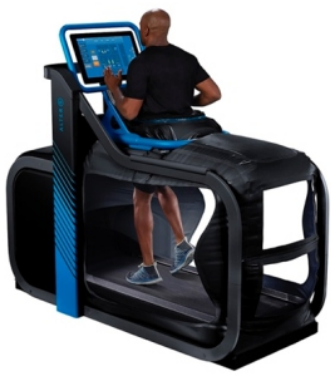

Figure 8: Alter G Treadmill.

for Cricket, Hockey, Football, Badminton, Tennis and Kabaddi, etc., have catapulted public interest in these sports. Awareness of physical fitness and health has made people embracing healthy physical activities such as Running, Cycling, Yoga, etc., Government of India has launched several measures for sports development including the Khelo India Scheme in 2016. The scheme aims to identify and promote sports talent in the young population and boost their mass participation in annual sports games and competitions. Sports are also being made as a compulsory subject in schools, as a part of the proactive measures of the Government $[6,7,8]$.

\section{National Centre of Sports Sciences} and Research (NCSSR)

Under the new NCSSR scheme, six universities and five medical colleges have been selected for establishing sports science and sports medicine departments. This NCSSR scheme of the Ministry of Youth Affairs and Sports has two features including setting up a center and providing funds to set up the sports science and medicine departments at the select universities. This scheme is administered by the Sports Authority of India (SAI) with a net amount of Rs. 62.61 crore released since the scheme's
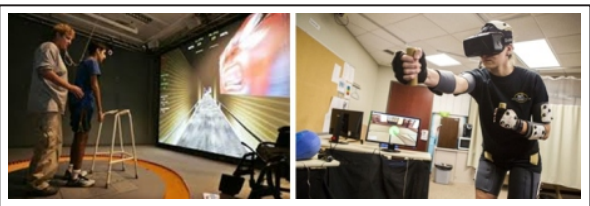

Figure 11: ( $a$ and b) Virtual Reality (VR) in sports rehabilitation and training.

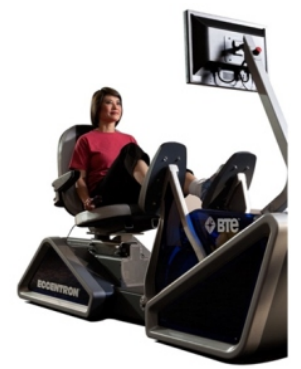

Figure 9: Eccentron trainer.

launch.

Central Athlete Injury Management System (CAIMS)

SAI, through its Athlete Wellness Cell, has launched the CAIMS. It is a referralbased injury and illness management system. The Athlete Wellness Cell is a step toward standardizing and reducing the geographical and administrative barriers to access the best in the country rehabilitation facilities, sports science evaluation and peak performance support centers along with round the year education and upgradation of athletes, coaches and support staff. The Athlete Wellness Cell will ensure that a developmental athlete can get assistance irrespective of his/her geographic location (SAI center/non-SAI Centre/Individual Training Centre/Home) for

- The best injury and rehabilitation experts of the country

- The best and latest scientific evaluation/peak performance experts/facilities.

The education programs organized through Athlete Wellness Cell will empower these athletes to better understand the scientific principles for peak performance with minimal injuries.

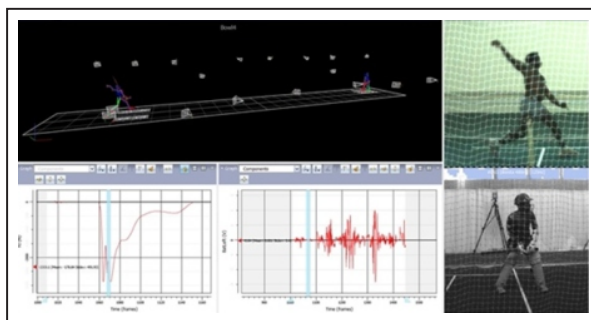

Figure 12: Sports Biomechanics Lab at CSS with 3-D motion analysis systems. 
The sports specific/domain specific experts can be made accessible to athletes to meet their specific needs and thus support them at right time with right resources at optimum expenditure.

Attractive awards and prizes for successful sports persons both by Government and corporate sectors are serving as inspiration for many sportspersons. The corporate and private sectors, as a part of their social responsibility measures, have been encouraged to focus on sports development and promotion. This has resulted in the establishment of some world class sports academies. Reservation for sports persons in employment opportunities has motivated many to take up sports. Athletes, as well as the public are becoming more aware of sports and exercise and recognize the importance of sports medicine. New leagues and the development of sports in general, plus the influx of money in different sports have made sports medicine a lucrative field.

\section{Components of Sports Medicine}

Sports Medicine is evolving faster than expected with the rise in popularity of sports and fitness. It is a multidisciplinary field with a broad objective, not only to treat injuries, but also to instruct and prepare athletes in a holistic way. A greater demand on sport, science, and medicine has influenced the related fields such as Exercise Physiology, Strength and Conditioning, Physical Therapy, Nutrition, Psychology, and Biomechanics to come together in cooperation and merge into Sports Medicine and Sports Science. A Sports Medicine physician is expected to undergo training and master the following components:

- Sports Injury and Medical illness prevention

- Injury diagnosis, Treatment and Rehabilitation

- Management of medical problems
- Performance Enhancement through training

- Nutrition and Psychology

- Exercise prescription in Health, Chronic states and for special subpopulations

- Medical care of sporting teams and events

- Medical care in situations of altered physiology such as altitude, environmental extremes, or at depth

- Dealing with ethical issues, such as the problem of drug abuse in sport (doping).

\section{The sports physician}

The sports physician will have working knowledge of various subjects including Sports Imaging, Sports Surgery, Pain management, post-surgical protocols, Recovery of activities of daily living, Recovery of sports specific fitness and skills and Prevention of re-injury. He will utilize this knowledge to develop the following competencies

- Prevention and treatment of sports related injuries by integrating applied anatomy, sports biomechanics, and relevant kinesiology

- Evidence-based approach to interpret and utilize published literature

- Function as a part of a team, develop an attitude of co-operation with colleagues, and interact with the patient and other colleagues to provide the best possible care

- Adopt ethical principles and maintain proper etiquette in dealings with athletes, patients, relatives and other health personnel and to respect the rights of the patient including the right to information and second opinion

- Communicate well to interact with patients, relatives, peers and paramedical staff, and for effective teaching

- Communicate effectively and appropriately with all the athletes, coaches and health professionals to maintain standards of best practice in Sports Medicine

- Design, implement, evaluate and modify injury prevention and management programs

- Do detailed and relevant musculoskeletal assessment, which are specific to the athlete.

The sports medicine physician would have to be trained in various fields of applied sports sciences and on-field at sports events. Apart from rotating in various medical departments such as Orthopedics, Cardiology, and General Medical and Emergency Care he will get requisite training in Sports Psychology and Exercise Physiology Laboratories, Kinanthropometry lab for body composition analysis, somatotyping and age determination, Biomechanics lab etc.,

\section{Role of the sports physician}

On the medical front, Sports Medicine had been limited to only treating sports injuries mainly. Only very few institutes were available for doctors to train in sports medicine. The concept of injury prevention and sports performance enhancement along with the high competition levels and the surge in number of sports events nowadays has resulted in the development of Sports Medicine as a distinct specialty. There are many more options for a medical doctor to pursue higher education in sports medicine now. The specialty has come into prominence after some unfortunate incidences on the field where sports persons have lost their lives, mostly due to preventable factors like Sudden Cardiac Death and Head injuries $[9,10]$.

As a Sports physician, it is duly one's duty to prepare the athlete's physical, mental and social health to be at his/her best thereby achieving their best performance. Sports physician is required to assume the role of a "Captain of the ship" many a times, while he needs to serve just as a member of the team at other times. The sports physician should always be prepared to make the right diagnosis, many a times instantly, on the field. The right diagnosis, though crucial, is only the first step. The diagnosis needs 
to be supplemented with a masterful coordinated strategy and execution of various interventions till the athlete recovers completely and returns to sport.

\section{Recent Advances in Sports Medicine}

\section{Injury prevention}

In the old school of sports medicine, injury treatment and rehabilitation were only focused, whereas the impetus is given to prevent the injuries happening in the first place. This is achieved through a multi-modal approach including various new strategies and technologies.

Technology can gather data about every aspect of the performance of the players either during training or the actual competition. With these data one can analyze, create new strategies and thus boost players' performance and can also monitor health state and warn about overstraining. Current technologies also dig deeper and discover what health risks they have in their genes or what nutrition they should follow to stay at the top.

Genetic technology companies work with athletes aiming to use collected DNA information to improve performance, health, and safety. These genetic tests could give additional information about any possible injury risk or specific nutritional issues and thus allow the scientists and support staff of the athlete to adjust the training methods and nutrition accordingly. Through a blood sample athlete's DNA could be analyzed and a personalized meal plan that works best for his or her body can be created. The spread of nutrigenomics could be of massive help for athletes to find the right diet boosting their performance to reach new records and make their immune systems stronger and prevent injuries.

Sensory garments, helmets, mouth guards

The Australian company, Catapult Sports (Fig. 2) is one of the biggest sports tracking devices manufacturers. Many leading professional teams use their trackers worldwide. The small, pocketsized GPS trackers can be worn on the back of players' training tops, and track over 100 variables, right from speed and heart rate to acceleration and other metrics. The coach and support staff can monitor their players' information on the sidelines in real time.

Zephyr Technology backed by Medtronic produces among others a bioharness, (Fig. 3) which allows coaches to see the intensity of a specific training regarding biomarkers, such as heart rate, temperature, or acceleration. The trauma-monitoring patches stick to the athlete's body to measure force and impact so that support staff could have data about concussion risks for football or hockey players.

\section{Monitoring health through sensors} and wearables

Today's wearables and sensors do a lot to support training and maintain the health of the athletes while helping them reach their very best through constant health data management, real-time performance monitoring, and feedback. Pebble time (Fig. 4) and the android sleep app follow sleeping habits.

Fitbit Surge or Fitbit Ionic tracking fitness activities (Fig. 5), while PIP gives an overview of stress levels.

There are many specialized tools for monitoring the stress load and performance of players to avoid fatigueinduced injuries. For example, athletes who do lots of jump roping during their training might want to try Vert (Fig. 6).

It helps them measure so that they could improve their jumping performance; and also know when they are nearing dangerous levels of fatigue that may, in turn, lead to injury. "Blast Motion" also does something similar. It can track and analyze players' swings during training to optimize performance asoon, will be able to show vital physiological data in realtime to the clinician standing at a playfield's sidelines. This would enable them to get an accurate picture of the individuals' status. When GPS data is added to this it may help to make informed decisions as to when to substitute the player in a match or to remove him from the field of play.

\section{High altitude training}

Altitude training has been used by endurance athletes to enhance performance. In the last decade or two, remarkable techniques have been introduced which are capable of "bringing the mountain to the athlete." Nitrogen houses, hypoxia tents, and special breathing apparatuses provide inspired hypoxia at rest and during exercise to simulate the critical elements of altitude training.

There are several methods of hypoxic exposure under the broad division of Either Natural Altitude Exposure or Simulated Hypoxic Exposure. Natural Altitude Exposure has been proven to be the most beneficial in terms of adaptations and performance enhancement. However, the difficulties faced by many athletes in traveling to such altitudes and staying there for prolonged periods had made this method least popular among them. Living and or training under simulated hypoxic conditions are the most popular among athletes at present (Fig. 7).

High Altitude Training results in following physiological advantages:

- Increase in the levels of red blood cell indices such as Hemoglobin, Red blood cell count, Hematocrit, Erythropoietin and Reticulocyte count

- Increase in maximal aerobic capacity (measured by VO2 max, Lactate threshold)

- Cardiopulmonary adaptations (Increased lung volumes)

- Genetic expression of hypoxia-related genes (HIF 1-alpha)

All the adaptations occurring over 8-10 weeks of training under hypoxia will lead to improvement of endurance 
performance compared to training at sea level.

\section{Newer rehabilitation techniques}

State-of-the-art equipment and appropriate rehabilitation tools could shorten the time of recovery and make the athletes to return to their sports earlier. Portable medical devices and realtime visualization are already making a difference, with musculoskeletal ultrasound being a stellar example.

\section{Anti-gravity treadmill, exoskeletons}

It takes a long time and intense rehabilitation process for returning to sports after a major injury. The AlterG Anti-Gravity Treadmill (Fig. 8) allows patients to work out without bearing their full body weight. This equipment can take over between 20 and $100 \%$ of the original weight enabling athletes to move muscles and bones without overstraining them. This treadmill is doing wonders in sports rehabilitation.

The Bionic Leg device provides patientinitiated motor assistance during sit-tostand exercises, walking, and stair climbing. It effectively strengthens weak muscles, improves balance, and helps patients to improve their gait quickly.

Complex robotic structures called Exoskeletons could also support rehabilitation in the future. The Baltimore-based BTE, offers such complex rehabilitation systems. It has various rehabilitation equipment such as the Primus RS dynamometer or the Eccentron, Resistance Trainer. The former evaluates patients' movements such as gripping and lifting so the clinician can assign the appropriate rehabilitation exercises. In case of the Eccentron, the exercising machine (Fig. 9) is an essential part of both rehabilitation and performance enhancement. It targets mainly eccentric exercises setting up an appropriate training program.
Future of sports medicine

Chips and clothing can measure vital signs and devices boosting performance actively. Many players in professional sports now wear unique shirts that measure their vital signs during practice and even games. HexoSkin (Fig. 10) has developed a shirt with multiple sensors woven into it to measures heart rate, breathing, number of steps, pace, and calories. D30 has introduced a smart material that provides shock absorption and impact protection capabilities, which are useful for basically every sport.

In the future, many high-contact sports will start utilizing "high-tech hard-hats" for providing safety. These helmets utilize shock absorbers that release air when the head suffers an impact. The air inflates the protective interior of the helmet and reduces the amount of jerky movement the head sustains, thereby reducing the chances of concussion. Special mouth guards have been developed now which can alert athletes about shock: sensors warn the player when an injury that could potentially lead to a concussion has occurred.

Augmented reality/virtual reality in sports medicine

Although virtual reality and augmented reality are already used in several medical specialties, their application in sports medicine is beginning to find its feet. Blending existing evidence-based rehabilitation strategies with cuttingedge VR technologies could replicate the players in their own stadium, and the noise of the fans would be a valuable adjunct.

There are some positive examples leading the way to the utilization of VR in sports medicine. Israeli start-up VRPhysio harnesses the power of gaming technology to help treat neck, spinal and other injuries through VR and rehabilitating games (Fig. 11a and b). It has made a platform that makes rehabilitation exercises easily accessible and enjoyable to patients. The rehab program can be easily monitored and a nalyzed by doctors and physiotherapists.

In the future, $\mathrm{VR} / \mathrm{AR}$ will be more visibly used in sports medicine. An augmented reality app is being launched which would help physicians check the collisions of players in real time, assess the impact and make the decision whether a player can continue or should be taken off the field. This app might be used both for training and in real sports events. Just as every other specialty, sports medicine will change a lot due to AR/VR, trackers, wearables or exoskeletons. The challenge is to learn how to use those technologies and to make sports medicine physicians better at their work without losing the human touch. The future indeed seems to be exciting!

\section{Center for Sports Science (CSS)}

CSS at Sri Ramachandra Institute of Higher Education and Research (deemed to be university) in Chennai is a premier institution which serves as a hub for Sports Science Training, Education and Research in India [11]. It is the first and only center of excellence for Asian Football Confederation and International Cricket Council in India. As an approved center or excellence for the SAI and for state governments of Tamil Nadu and Kerala, CSS is involved in various a multitude of sports development projects. It has state of the art sports science labs for 3D Biomechanics (Fig. 12), Exercise Physiology, Anthropometry, Psychology, Isokinetic Dynamometry, High Altitude Training, and Sports Podiatry along with international standard indoor and outdoor sport facilities. CSS is home to various sports academies including the Government of India approved "Khelo India" multisport academy and other academies for Hockey, Shooting, Rowing, Cricket, Basketball, Mixed Martial Arts, Swimming, Tennis and Badminton. 
CSS has collaborations with international institutions at South Africa, Australia, UK and leading national institutions such as the Netaji Subhas National Institute of Sports, Patiala, Army Sports Institute, Pune, Guru Nanak Dev University, Punjab and the Rajiv Gandhi Central University, Arunachal Pradesh. Though these collaborations, CSS offers various sports science courses at UG and PG levels. Advanced level certificate courses in
Sports Physiotherapy, Sports Nutrition, Sports Psychology and Strength and Conditioning are jointly offered with National Institute of Sports, Patiala. MD Sports Medicine postgraduate level course for medical doctors was first started in India at this institute.

\section{The final whistle}

The evolution of sports, from just as a source of entertainment to that of a social culture and as a career option for many, has been a very gratifying development. This trend is expected to evolve further with the bright scope for everyone connected to the sports ecosystem, right from the sports persons to the sports science professionals. Upskilling at individual levels and upgrading at institutional levels has thus become indispensable. We can surely expect India to emerge as a force to reckon with in the field of sports to soon.

Declaration of patient consent: The authors certify that they have obtained all appropriate patient consent forms. In the form, the patient has given his consent for his images and other clinical information to be reported in the Journal. The patient understands that his name and initials will not be published, and due efforts will be made to conceal his identity, but anonymity cannot be guaranteed.

Conflict of Interest: NIL; Source of Support: NIL

\section{References}

1. American College of Sports Medicine-ACSM. Available from: https://www.acsm.org Last accessed on 15.10.2021

2. Australasian College of Sport and Exercise Physicians-ACSEP. Available from: https://www.acsep.org.au Last accessed on 15.10.2021

3. International Olympic Committee-medical and Scientific Co m m is sion. A v a i l a ble form: https://www.olympics.com/ioc/medical-and-scientificcommission Last accessed on 15.10.2021

4. FIFA Medical Commission. Available form: https://www.fifa.com/about-fifa/medical Last accessed on 15.10.2021

5. FICCI. Tanjun Associates Study on Sports as a Full Time Career. New Delhi: FICCl; 2011.

6. Khandare RB. A study of physical tutoring and sporting in India. J
Sports Phys Educ 2016;3:1-3.

7. Banerjee A. Governmental Initiatives to Promote Sports in India. A v a i l a b l e form : https://www.sportskeeda.com/athletics/governmentalinitiatives-to-promote-sports-in-india [Last accessed on 2019 Feb 21].

8. Chellathurai P. Sport in modern India: Policies, practices and problems. Int J Hist Sport 2002; 19:366-83.

9. Vaishya R, Dhammi IK. Upsurge of sports injuries and their treatment. Indian J Orthop 2017;51:485-6.

10. Dhillon H, Dhillon S, Dhillon MS. Current concepts in sports injury rehabilitation. Indian J Orthop 2017;51:529-36.

11. Centre for Sports Science, SRIHER (DU). Available form: https://www.csstrucoach.in Last accessed on 15.10.2021.
Conflict of Interest: NIL

Source of Support: NIL

\section{How to Cite this Article}

Sivaraman A, Perumal S, Ayyathurai P, Alwar T. Development of Sports Medicine in India and Recent Advances. Journal of Clinical Orthopaedics JulyDec 2021;6(2):35-41. 